Int. J. Dev. Biol. 51: 235-240 (2007)

doi: $10.1387 / \mathrm{ijdb} .062236 \mathrm{rm}$

Developmental Expression Pattern

\title{
The Xenopus ortholog of the nuclear hormone receptor Nr2e3 is primarily expressed in developing photoreceptors
}

\author{
REYNA I. MARTINEZ-DE LUNA and HEITHEM M. EL-HODIRI*,1,2 \\ Graduate Program in Molecular, Cellular and Developmental Biology, College of Biological Sciences, The Ohio State University, \\ ${ }^{1}$ Center for Molecular and Human Genetics, Columbus Children's Research Institute and ${ }^{2}$ Department of Pediatrics, College of Medicine \\ and Public Health, The Ohio State University, Columbus, OH, USA.
}

\begin{abstract}
Nr2e3 is a nuclear hormone receptor that is involved in rod photoreceptor differentiation. The Nr2e3 gene was previously identified in humans, mice, zebrafish and chicken. In all species, Nr2e3 expression is restricted to the retina and is believed to have a role in rod photoreceptor specification and maintenance. Here we report the identification and characterization of the Xenopus Nr2e3. We found that Nr2e3 is primarily expressed in developing rod photoreceptors. In contrast to other species, $\mathrm{Nr2e} 3$ is also expressed in the notochord and pineal gland during Xenopus laevis development.
\end{abstract}

KEY WORDS: Nr2e3, nuclear hormone receptor, photoreceptor, retina, pineal gland, notochord, Xenopus

Nr2e3belongs to the superfamily of nuclear hormone receptors that function as ligand-dependent transcription factors (Escriva et al., 2000, Kobayashi et al., 1999). Nuclear receptors all share three canonical domains: an $\mathrm{N}$-terminal variable domain, a zinc finger DNA binding domain (DBD) and a ligand binding domain (LBD) (Escriva et al., 2000, Zhao et al., 1998). Despite their common structure, nuclear receptors have distinct functions in different tissues (Escriva etal., 2000, Giguere, 1999, Kobayashi et al., 1999).

Many of the nuclear receptors identified to date, including $\mathrm{Nr2e}$, lack a known ligand and are thus named orphan nuclear receptors (Giguere, 1999). The superfamily of orphan nuclear receptors includes COUP TF/(Nr2f1), COUP TF//(Nr2f2) and T/X (Nr2e 1), a homolog of the Drosophila terminal/gap gene tailless (Chen et al., 2005, Kobayashi et al., 1999). Nr2e3was initially identified for its sequence similarity to T/x (Nr2e 1) (Kobayashi et al., 1999).

Nr2e3expression was found to be restricted to the retina and observed only in the outer nuclear layer (ONL) where the nuclei of photoreceptors are located (Chen et al., 2005, Kobayashi et al., 1999). It was initially observed in the human retina that Nr2e3is specifically expressed in rod photoreceptors (Bumsted O'Brien et al., 2004) and later the same pattern of expression was observed in the rodent retina (Cheng et al., 2004).

In the embryonic mouse retina, Nr2e3 expression is observed early in rod precursors between E18.0-18.5, before the expression of any rod differentiation markers (Chen et al., 2005, Cheng et al., 2004). Similarly, in the developing zebrafish retina $N$ r2e3expression becomes restricted to rod photoreceptors by 4 days post-fertilization (dpf), although transient expression of $\mathrm{Nr2e} 3$ was detected in both cone and rod photoreceptors at $2 \mathrm{dpf}$ (Chen et al., 2005). Functionally, Nr2e3 has been established to be a transcriptional activator of rod photoreceptor genes (Cheng et al., 2004, Peng et al., 2005). Nr2e3 heterodimerizes with $\mathrm{Nr} 1 \mathrm{~d} 1$ and in conjunction with $\mathrm{Crx}$ and $\mathrm{Nrl}$, regulates the activity of the Rhodopsin promoter (Cheng et al., 2004).

Enhanced S-cone syndrome (ESCS) is an autosomal recessive hereditary disease in which the S-cones (blue) are hypersensitive (Jacobson et al., 1991, Marmor et al., 1990). The hypersensitivity of S-cones in ESCS is due to a greater number of S-cones than the more normally abundant $\mathrm{L}$ or $\mathrm{M}$-cones (Hood et al., 1995). In humans, different mutations in NR2E3 have been correlated with ESCS (Haider et al., 2000, Hayashi etal., 2005, Milam etal., 2002, Nakamura etal., 2002, Nakamura et al., 2004, Sharon et al., 2003, Wright et al., 2004), although mutations in NRL have also been correlated with ESCS (Wright et al., 2004). In many of the cases where the NR2E3 gene is mutated, an increased number of S-cones, retinal dysplasia and degeneration was observed (Haider et al., 2000). Mice harboring the naturally occurring $r d 7$ mutation also exhibit retinal dysplasia and degeneration (Akhmedov et al., 2000, Haider et al., 2001), reminiscent of the phenotype of the mutations observed in humans. Later studies showed that $r d 7$ mice harbor a deletion encompassing exons 4 and 5 of the Nr2e3 message (Akhmedov et al., 2000, Haider et al., 2001)

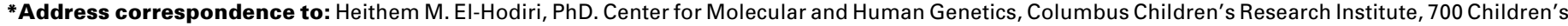
Drive, Columbus, OH 43205, USA. Fax: +1-614-722-2817. e-mail: elh@ccri.net
} 


\section{A}

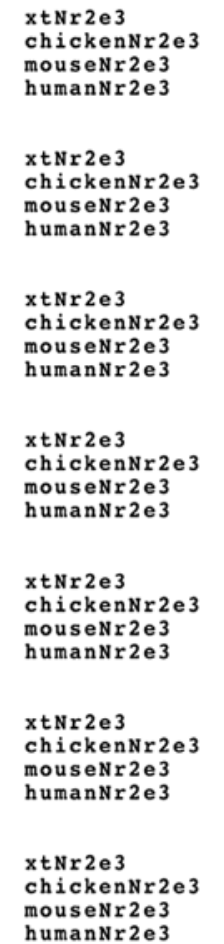
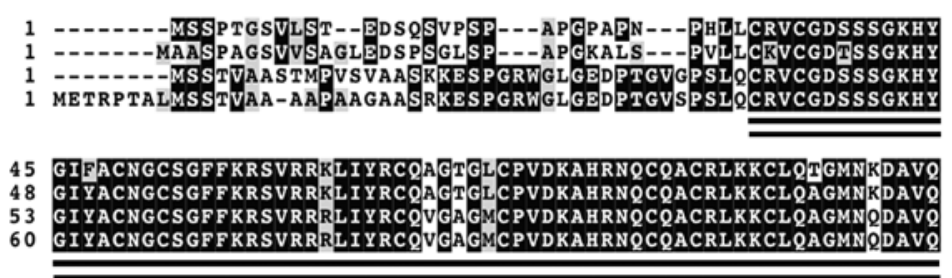

105 NERQPRSTAQI RLDSI DLDTDSRSERLA TTRDPPPS -CPQGN - NLRTP I P SAI S GTLSPP

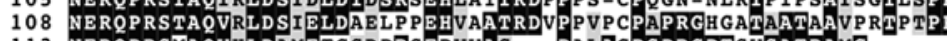

113 NERQPRSMAQVHLDAMETGSDPRSEPVVAS -- PALAGPSPRGPTSVSATRAMG--120 NERQPRSTAQVHLDSMESNTESRPESLVAP - - PAPAGRSPRGPTPMSAARALG-.-.-

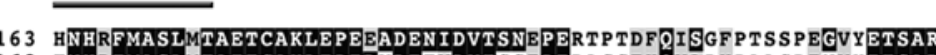

163 HNHRFMASLMTAETCAKLEPEEADENIDVTSNEPERTPTDF RISGFPTSSPEGVYETSA 168 TNHRFMASLMTAETCAKLEPEDVDETVDVTGGEPERAGGEYQVAPY PAAGPENVYETSA $\begin{array}{ll}164 & - \text {-HHFMASLITAETCAKLEPEDAEEN I DVTSNDPEF - } \\ 171 & - \text {-HHFMASLITAETCAKLEPEDADENIDVTSNDPEFPS--SPYSSSSPCGLDSIHETSAR }\end{array}$
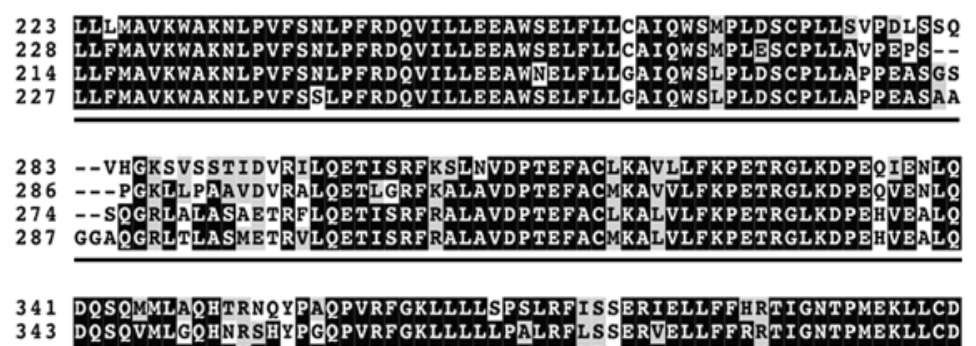
332 DQSQVMLSQHSKAHHP SQPVRF GKLLLLLP SLRFLTAERIELLFF RKT I GNTPMEKLLCD 347 DQSQVMLSQH KAHHPSQPVRF GKLLLLLPSLRF I TAER I ELLFFRKT I GNT PMEKLLCD

\begin{tabular}{lll} 
xtNr2e3 & 401 & MFKN \\
chickenNr2e3 & 403 & MFKN \\
mousenr2e3 & 392 & MFKN \\
humanNr2e3 & 407 & MFKN \\
\hline
\end{tabular}

B

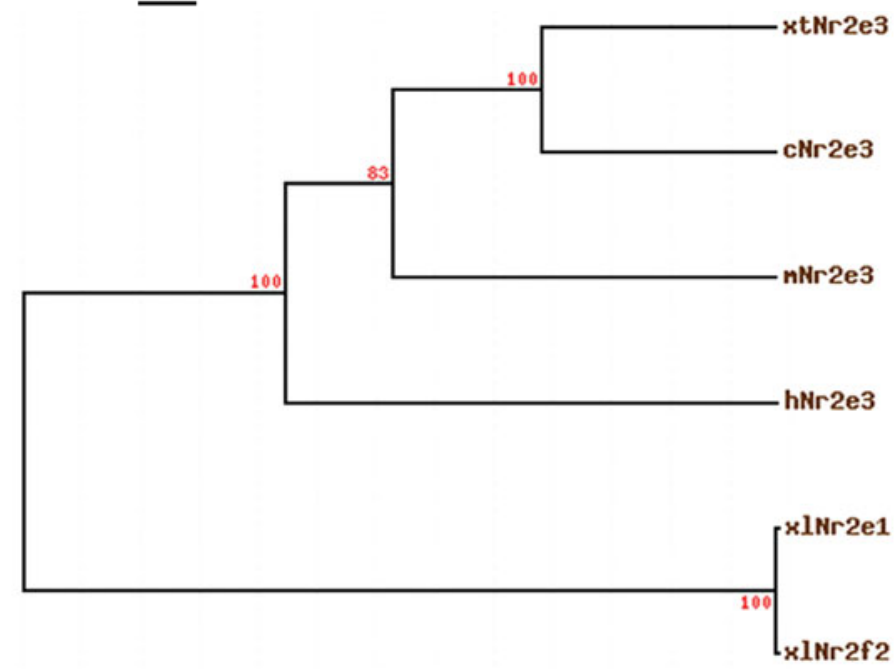

0 0.1 0.2 0.3 0.4 0.5 0.6

Fig. 1. Amino acid sequence comparison of Nr2e3 between different species. (A) The sequence of the Xenopus tropicalis $\mathrm{Nr2e} 3$ (xtNr2e3) gene product (Accession number: DQ906161) is compared to that of the chicken, mouse and human. Single underline denotes the conserved ligand binding domain ( $L B D)$ and the double underline denotes the conserved DNA binding domain (DBD). (B) Phylogenic analysis of xtNr2e3 and the related orphan nuclear receptors Nr2e1 (TIX) and Nr2f2 (COUP TF II). Phylogenetic analysis was performed from ClustalW alignment using the Phylip tree format in the Tree Top program (http:// www.genebee.msu.su/services/phtree_reduced.html). Species abbreviations: $x t$, Xenopus tropicalis; c, chicken; $m$, mouse; $h$, human; $x l$, Xenopus laevis. and causes excess cone cell proliferation (Akhmedov et al., 2000, Haider et al., 2001).

Here we report for the first time the identification and characterization of the Xenopus tropicalis Nr2e3ortholog. We also examine the expression pattern of $\mathrm{Nr} 2 \mathrm{e} 3$ during Xenopus laevis development.

\section{Results and Discussion}

The predicted $X$. tropicalis $\mathrm{Nr2e} 3(\mathrm{xtNr} 2 \mathrm{e} 3)$ gene product is most similar $(76 \%)$ to the published chicken Nr2e3 protein (Figure 1A), but also has a high degree of sequence conservation with the mouse $(68 \%)$ and human $(67 \%)$ Nr2e3 proteins (Figure 1A). $x+N r 2 e 3$ encodes both a canonical DBD and LBD that are found throughout the orphan nuclear receptor superfamily of proteins (Figure $1 \mathrm{~A}$ ). In a phylogenetic analysis, xtNr2e3 is clustered with $\mathrm{Nr2e} 3$ from other species and it is excluded from the $X$. laevis $\mathrm{Nr2e} 1$ (TIX) and Nr2f2 branches (Figure 1B). These findings suggest that our isolated clone encodes the frog ortholog of Nr2e3, since it is most closely related to the other vertebrate Nr2e3 gene products.

During $X$. laevis development, the expression of $N$ r2e 3 is first observed at stage 30/31 in the center of the eye (Figure 2A). In sections taken from the wholemount in situ embryos, Nr2e3expression can be confirmed to be present in the central retina (Figure $2 \mathrm{H}$ ). This pattern of Nr2e3 expression is consistent with the development of the retina in a central-to-peripheral manner (Rapaport and Stone, 1984, Stone et al., 1985), with photoreceptor cell birth following the same pattern of development (Chang and Harris, 1998, Rapaport et al., 2001). At stage 33/34, Nr2e3 expression is no longer observed in the central retina, but is expressed strongly in the developing peripheral retina (Figure 2B). By stage 35/36, Nr2e3 expression is observed only in the neural retina and is clearly excluded from the lens (Figure $2 \mathrm{C}$ arrow). This expression pattern differs from that of $T / x$ (Nr2e1), which is expressed in the retina, forebrain and midbrain between stages 30/ 31 to 35/36 (Figure 2 D-F) (Hollemann et al., 1998). Nr2e3 expression was also observed in the pineal gland (Figure $2 \mathrm{~A}-\mathrm{C}$ arrowheads). The pineal gland contains photoreceptor-like cells (Vigh et al., 2002) and the expression of $\mathrm{Nr2e3}$ in this organ is similar to the expression of $R x$ in the pineal gland at this stage (Figure 2G arrow) (Casarosa et al., 1997, Mathers et al., 1997). In addition, Nr2e3 expression was also detected in the 

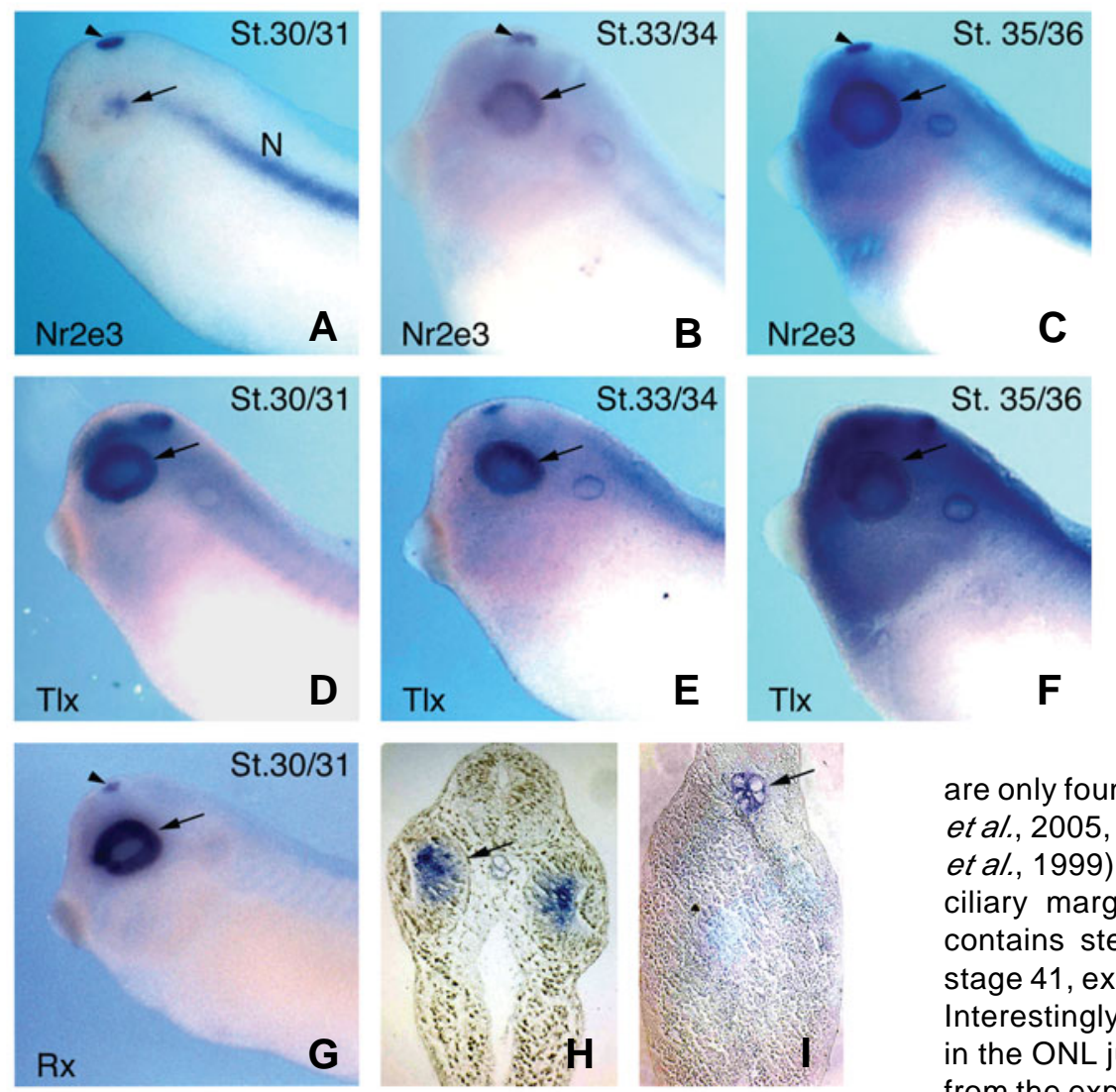

notochord of the developing embryos (Figure $2 \mathrm{~A}-\mathrm{C}$, l-arrow). Expression of $N r 2 e 3$ in pineal gland and notochord has not been reported in other species.

To further analyze the expression of Nr2e3in the developing retina at later developmental stages, we performed in situ

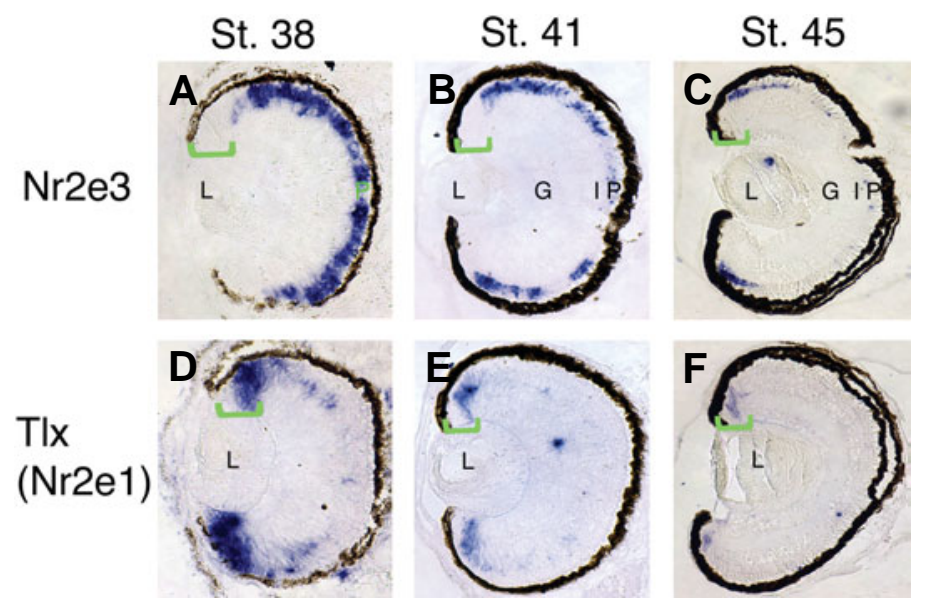

Fig. 2. Expression of $\mathrm{Nr2e3}$ in $\mathrm{X}$. laevis embryos during development. (A-H) Lateral views of embryos subjected to wholemount in situ hybridization using antisense riborprobes specific for $\mathrm{Nr} 2 \mathrm{e} 3$ (A-C), TIx (D-F), or Rx (G). Arrow denotes retinal expression and the arrowhead denotes pineal gland expression. (H, I) Transverse sections of an embryo at stage 30/31 after wholemount in situ hybridization. (H) Transverse section through the head showing retinal expression (arrow). (I) Transverse section around the gut area showing strong notochord expression (arrow). In (A$G)$, riboprobes and developmental stages are indicated in the lower left and upper right corner of each panel, respectively.

hybridization on retinal sections of embryos at stages 38, 41 and 45 (Figure 3). At stage 38, when the retina is not yet obviously laminated, Nr2e3expression is very robust in the photoreceptor layer (Figure 3A), consistent with the previous observation that $\mathrm{Nr2e} 3$ transcripts are only found in photoreceptors (Akhmedov et al., 2000, Chen et al., 2005, Haider et al., 2000, Haider et al., 2001, Kobayashi et al., 1999). However, Nr2e3 expression is excluded from the ciliary marginal zone (CMZ), the region of the retina that contains stem cells and retinal progenitors (Figure $3 \mathrm{~A}$ ). By stage 41, expression of $\mathrm{Nr2e} 3$ is apparent throughout the ONL. Interestingly, by stage 45, Nr2e3expression was only observed in the ONL just adjacent to the CMZ (Figure $3 \mathrm{C}$ ), which differs from the expression of $N r 2 e 3$ in the rodent and zebrafish retina where $\mathrm{Nr} 2 \mathrm{e} 3$ is expressed throughout the ONL once photoreceptors have differentiated and matured (Chen et al., 2005, Cheng et al., 2004). In contrast, T/x expression is restricted to the CMZ, where Nr2e 3 is absent (Figure $3 \mathrm{D}-\mathrm{F}$ ). T/x expression decreases as development progresses (Figure 3D-3F).

Double in situhybridization showed overlapping expression of Nr2e3 and Rhodopsin in the ONL at stage 45 (Figure 4A, B arrow). Nr2e3expression is observed in the photoreceptor cell body, since $\mathrm{Nr2e} 3$ transcripts are restricted to photoreceptors (Akhmedov et al., 2000, Chen et al., 2005, Haider et al., 2001, Kobayashi et al., 1999). Interestingly, co-expression of Rhodopsin and Nr2e 3 is observed in rods at the periphery of the neural retina, but excluding the CMZ (Figure 4B). Nr2e3 is expressed in rod precursors before differentiation and prior to expression

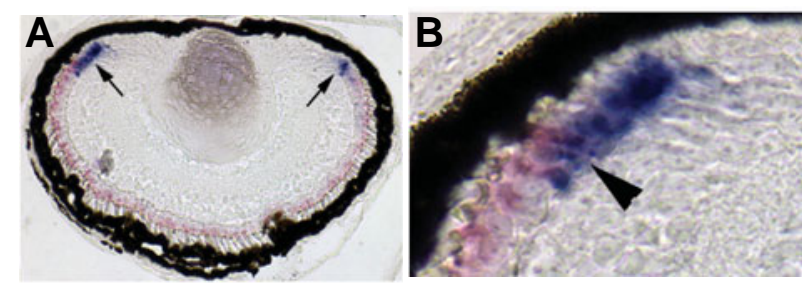

Fig. 3. (Left) $\mathbf{N r 2 e 3}$ and $\mathbf{T I x}$ (Nr2e1) expression in retinal sections. In situ hybridization using paraffin sections of embryos at various stages during $\mathrm{X}$. laevis development probed for $\mathrm{Nr} 2 \mathrm{e} 3$ (A-C) and $\mathrm{TIx}$ ( $\mathrm{Nr2e} 1$ ) (D-F) expression. Nr2e3 is expressed in the neural retina, but not in the CMZ (A-C). Retinal expression of Tlx is restricted to the CMZ by stage 45 (arrows in (D-F). Retinal layers and the lens are labeled with a letter abbreviation: $L$, lens; $G$, ganglion cell layer; I, inner nuclear layer; $P$, photoreceptor layer.

Fig. 4. (Right) Co-expression of $\mathbf{N r 2 e} 3$ and Rhodopsin in rods. (A) Double in situ hybridization for Nr2e3 (purple) and Rhodopsin (red) in a section of an eye from a stage 45 embryo. Arrows denote the overlap between Nr2e3 and Rhodopsin expression. (B) Higher magnification (optical and digital) of the picture in (A) showing the region of overlap between $\mathrm{Nr} 2 \mathrm{e} 3$ and Rhodopsin expression (arrowhead). 
of Rhodopsin, which is first detected at stage 33/34 in Xenopus laevis (Chang and Harris, 1998).

\section{Materials and Methods}

\section{Isolation and cloning of the $\mathrm{X}$. tropicalis $\mathrm{Nr2 \textrm {e }} 3$ ortholog}

A BLAT search of the Xenopus tropicalis genome in the DOE Joint Genome Institute (JGI) website (http://www.jgi.doe.gov/) yielded a genomic locus for the Nr2e3 gene (Scaffold 103: 742787-749884). By sequence comparison of the intron and exon arrangements of the chicken Nr2e3, primers (5'- caatgagttctcccacaggatc; 3'gatttagttcttgaacatatcacaaag) were designed against the first exon and last exon predicted by the BLAT search. Total mRNA was purified from heads isolated from stage 38 Xenopus tropicalis tadpoles (NASCO Sciences; Fort Atkinson, WI, USA) using TRIZOL (Invitrogen). RT-PCR was performed from the total RNA using the SuperScript One Step RT PCR Kit (Invitrogen). The amplified product was subcloned (TOPO TA Kit, Invitrogen), sequenced and confirmed to be full length Nr2e3 (Submitted to PubMed; accession number: DQ906161). Nr2e3 sequences were aligned using the ClustalW program from the European Bioinformatics Institute (EBI) website (http://www.ebi.ac.uk/clustalw/).

\section{In situ hybridization}

The Nr2e3 probe used for wholemount in situ hybridization was generated from a Xenopus laevis expressed sequence tag (EST) (Accession number: CD328661) that was identified by its degree of sequence homology to the chicken Nr2e3 gene product in a BLAST search. To generate the riboprobe the Nr2e3est/pCMV-Sport6-ccdb plasmid was cut with using Notl and EcoRI restriction enzymes (New England Biolabs) to release the predicted coding sequence from the EST. The excised coding region from the Nr2e3est/pCMV-Sport6-ccdb plasmid was then cloned into the Notl and EcoRI sites of pBlueScriptll KS to generate the plasmid Nr2e3cds/pBlueScript. Nr2e3cds/ pBlueScript was then linearized with EcoRI (New England Biolabs) and the antisense riboprobe made using T7 RNA polymerase plus (Ambion). Antisense riboprobes for Rhodopsin, TIX, Rx were generated as described previously (Hollemann et al., 1998, Mathers et al., 1997, Pan et al., 2006, Zuber et al., 2003).

Embryos were generated by in vitro fertilization (Sive et al., 2000), staged and fixed as described previously (Nieuwkoop and Faber, 1994, Sive et al., 2000). Wholemount in situ was performed using whole embryos as previously described using digoxigenin-labeled antisense riboprobes (Sive et al., 2000, Turner and Weintraub, 1994). Briefly, hybridization and post-hybridization washes were performed at $65^{\circ} \mathrm{C}$ and after color reaction in BM-Purple (Roche) the embryos were postfixed in Modified Bouin's fixative (picric acid was omitted), dehydrated and bleached (Seufert et al., 2005, Shimamura et al., 1994). For section in situ hybridization, paraffin sections $(8 \mu \mathrm{m})$ of retinas were processed using digoxigenin-labeled antisense riboprobes as previously described (Shimamura et al., 1994, Viczian et al., 2003). Double section in situ hybridization was performed using digoxigenin-labeled Nr2e3 and fluorescein-labeled Rhodopsin antisense riboprobes $(2 \mu \mathrm{g} /$ $\mathrm{ml}$ each). After hybridization, the retinal sections were incubated with anti-digoxigenin-AP antibody overnight (Roche), followed by the color reaction with BM Purple (Roche). After color development, sections were subjected to post-hybridization washes (beginning after RNase treatment) and incubated with anti-fluorescein-AP antibody (Roche) overnight. Rhodopsin expression was visualized using Vector Red alkaline phosphatase substrate (Vector Laboratories).

\section{Acknowledgements}

We would like to thank Michael E. Zuber who kindly provided us with the Xenopus TIx plasmid. We would also like to thank Holly Moose and Lisa Kelly for critical reading of this manuscript. Also, we want to thank
Srivamsi Nekkalapudi and Lisa Kelly for expert technical assistance and Yi Pan for providing the Xenopus tropicalis CDNA. Lastly, we thank Vera Mcllvain for helpful discussions and the sharing of unpublished results. This work was supported by NIH/NEI grant EY015480 to HME.

\section{References}

AKHMEDOV, N.B., PIRIEV, N.I., CHANG, B., RAPOPORT, A.L., HAWES, N.L., NISHINA, P.M., NUSINOWITZ, S., HECKENLIVELY, J.R., RODERICK, T.H., KOZAK, C.A. et al. (2000). A deletion in a photoreceptor-specific nuclear receptor mrna causes retinal degeneration in the rd7 mouse. ProcNat/Acad SCi USA 97: 5551-6.

BUMSTED O'BRIEN, K.M., CHENG, H., JIANG, Y., SCHULTE, D., SWAROOP, A. and HENDRICKSON, A.E. (2004). Expression of photoreceptor-specific nuclear receptor nr2e3 in rod photoreceptors of fetal human retina. Invest Ophthalmol Vis Sci 45: 2807-12.

CASAROSA, S., ANDREAZZOLI, M., SIMEONE, A. and BARSACCHI, G. (1997). $\mathrm{Xrx1}$, a novel xenopus homeobox gene expressed during eye and pineal gland development. Mech Dev61: 187-98.

CHANG, W.S. and HARRIS, W.A. (1998). Sequential genesis and determination of cone and rod photoreceptors in xenopus. J Neurobio/35: 227-44.

CHEN, J., RATTNER, A. and NATHANS, J. (2005). The rod photoreceptor-specific nuclear receptor nr2e3 represses transcription of multiple cone-specific genes. $J$ Neurosci 25: 118-29.

CHENG, H., KHANNA, H., OH, E.C., HICKS, D., MITTON, K.P. and SWAROOP, A. (2004). Photoreceptor-specific nuclear receptor nr2e3 functions as a transcriptional activator in rod photoreceptors. Hum Mol Genet 13: 1563-75.

ESCRIVA, H., DELAUNAY, F. and LAUDET, V. (2000). Ligand binding and nuclear receptor evolution. Bioessays 22: 717-27.

GIGUERE, V. (1999). Orphan nuclear receptors: From gene to function. Endocr Rev 20: 689-725.

HAIDER, N.B., JACOBSON, S.G., CIDECIYAN, A.V., SWIDERSKI, R., STREB, L.M., SEARBY, C., BECK, G., HOCKEY, R., HANNA, D.B., GORMAN, S. et al. (2000). Mutation of a nuclear receptor gene, nr2e3, causes enhanced s cone syndrome, a disorder of retinal cell fate. Nat Genet 24: 127-31.

HAIDER, N.B., NAGGERT, J.K. and NISHINA, P.M. (2001). Excess cone cell proliferation due to lack of a functional $\mathrm{nr} 2 \mathrm{e} 3$ causes retinal dysplasia and degeneration in rd7/rd7 mice. Hum Mol Genet 10: 1619-26.

HAYASHI, T., GEKKA, T., GOTO-OMOTO, S., TAKEUCHI, T., KUBO, A. and KITAHARA, K. (2005). Novel nr2e3 mutations (r104q, r334g) associated with a mild form of enhanced s-cone syndrome demonstrate compound heterozygosity. Ophthalmology 112: 2115 .

HOLLEMANN, T., BELLEFROID, E. and PIELER, T. (1998). The xenopus homologue of the drosophila gene tailless has a function in early eye development. Development 125: 2425-32.

HOOD, D.C., CIDECIYAN, A.V., ROMAN, A.J. and JACOBSON, S.G. (1995). Enhanced $s$ cone syndrome: Evidence for an abnormally large number of $s$ cones. Vision Res 35: 1473-81.

JACOBSON, S.G., ROMAN, A.J., ROMAN, M.I., GASS, J.D. and PARKER, J.A. (1991). Relatively enhanced s cone function in the goldmann-favre syndrome. Am J Ophthalmo/111: 446-53.

KOBAYASHI, M., TAKEZAWA, S., HARA, K., YU, R.T., UMESONO, Y., AGATA, K., TANIWAKI, M., YASUDA, K. and UMESONO, K. (1999). Identification of a photoreceptor cell-specific nuclear receptor. Proc Nat/ Acad Sci USA 96: 48149.

MARMOR, M.F., JACOBSON, S.G., FOERSTER, M.H., KELLNER, U. and WELEBER, R.G. (1990). Diagnostic clinical findings of a new syndrome with night blindness, maculopathy and enhanced s cone sensitivity. Am J Ophthalmol 110: 124-34.

MATHERS, P.H., GRINBERG, A., MAHON, K.A. and JAMRICH, M. (1997). The rx homeobox gene is essential for vertebrate eye development. Nature 387: 6037.

MILAM, A.H., ROSE, L., CIDECIYAN, A.V., BARAKAT, M.R., TANG, W.X., GUPTA, N., ALEMAN, T.S., WRIGHT, A.F., STONE, E.M., SHEFFIELD, V.C. et al. (2002). The nuclear receptor nr2e3 plays a role in human retinal photoreceptor 
differentiation and degeneration. Proc Nat/ Acad Sci USA 99: 473-8.

NAKAMURA, M., HOTTA, Y., PIAO, C.H., KONDO, M., TERASAKI, H. and MIYAKE, Y. (2002). Enhanced s-cone syndrome with subfoveal neovascularization. Am J Ophthalmo/133: 575-7.

NAKAMURA, Y., HAYASHI, T., KOZAKI, K., KUBO, A., OMOTO, S., WATANABE, A., TODA, K., TAKEUCHI, T., GEKKA, T. and KITAHARA, K. (2004). Enhanced $\mathrm{s}$-cone syndrome in a japanese family with a nonsense nr2e3 mutation (q350x). Acta Ophthalmol Scand 82: 616-22.

NIEUWKOOP, P.D. and FABER, J. (1994). Normal table of xenopus laevis (daudin). Garland Publishing, Inc., New York.

PAN, Y., NEKKALAPUDI, S., KELLY, L.E. and EL-HODIRI, H.M. (2006). The rx-like homeobox gene ( $r x-I)$ is necessary for normal photoreceptor development. Invest Ophthalmol Vis Sci47: 4245-4253.

PENG, G.H., AHMAD, O., AHMAD, F., LIU, J. and CHEN, S. (2005). The photoreceptor-specific nuclear receptor nr2e3 interacts with crx and exerts opposing effects on the transcription of rod versus cone genes. Hum Mol Genet 14: 74764.

RAPAPORT, D.H., PATHEAL, S.L. and HARRIS, W.A. (2001). Cellular competence plays a role in photoreceptor differentiation in the developing xenopus retina. J Neurobio/49: 129-41.

RAPAPORT, D.H. and STONE, J. (1984). The area centralis of the retina in the cat and other mammals: Focal point for function and development of the visual system. Neuroscience 11: 289-301.

SEUFERT, D.W., PRESCOTT, N.L. and EL-HODIRI, H.M. (2005). Xenopus aristaless-related homeobox (xarx) gene product functions as both a transcriptional activator and repressor in forebrain development. Dev Dyn232: 313-24.

SHARON, D., SANDBERG, M.A., CARUSO, R.C., BERSON, E.L. and DRYJA, T.P. (2003). Shared mutations in nr2e3 in enhanced s-cone syndrome, goldmannfavre syndrome and many cases of clumped pigmentary retinal degeneration. Arch Ophthalmol121: 1316-23.

SHIMAMURA, K., HIRANO, S., MCMAHON, A.P. and TAKEICHI, M. (1994). Wnt1-dependent regulation of local e-cadherin and alpha $n$-catenin expression in the embryonic mouse brain. Development 120: 2225-34.
SIVE, H.L., GRAINGER, R.M. and HARLAND, R.M. (2000). Early development of xenopus laevis: A laboratory manual. Cold Spring Harbor Laboratory Press, Cold Spring Harbor, NY.

STONE, J., EGAN, M. and RAPAPORT, D.H. (1985). The site of commencement of retinal maturation in the rabbit. Vision Res 25: 309-17.

TURNER, D.L. and WEINTRAUB, H. (1994). Expression of achaete-scute homolog 3 in xenopus embryos converts ectodermal cells to a neural fate. Genes Dev8: 1434-47.

VICZIAN, A.S., VIGNALI, R., ZUBER, M.E., BARSACCHI, G. and HARRIS, W.A. (2003). Xotx5b and xotx2 regulate photoreceptor and bipolar fates in the xenopus retina. Development 130: 1281-94.

VIGH, B., MANZANO, M.J., ZADORI, A., FRANK, C.L., LUKATS, A., ROHLICH, P., SZEL, A. and DAVID, C. (2002). Nonvisual photoreceptors of the deep brain, pineal organs and retina. Histol Histopatho/17: 555-90.

WRIGHT, A.F., REDDICK, A.C., SCHWARTZ, S.B., FERGUSON, J.S., ALEMAN, T.S., KELLNER, U., JURKLIES, B., SCHUSTER, A., ZRENNER, E., WISSINGER, B. et al. (2004). Mutation analysis of nr2e3 and $\mathrm{nrl}$ genes in enhanced s cone syndrome. Hum Mutat 24: 439.

ZHAO, Q., KHORASANIZADEH, S., MIYOSHI, Y., LAZAR, M.A. and RASTINEJAD, F. (1998). Structural elements of an orphan nuclear receptor-DNA complex. Mol Cel/1: 849-61.

ZUBER, M.E., GESTRI, G., VICZIAN, A.S., BARSACCHI, G. and HARRIS, W.A. (2003). Specification of the vertebrate eye by a network of eye field transcription factors. Development 130: 5155-67.

Received: 4th October 2006 Reviewed by Referees: 19th October 2006 Modified by Authors and Accepted for Publication: 19th October 2006

Published Online: X April 2007 Edited by: Thomas D. Sargent 


\section{Previously published, related Int. J. Dev. Biol. articles}

See our Special Issue on Eye Development edited by J. Piatigorsky and R. Granger at:

http://www.ijdb.ehu.es/web/contents.php?vol=48\&issue=8-9

The signal transducing photoreceptors of plants

Keara A. Franklin, Victoria S. Larner and Garry C. Whitelam

Int. J. Dev. Biol. (2005) 49: 653-664

Xenopus laevis FoxE1 is primarily expressed in the developing pituitary and thyroid

Heithem M. El-Hodiri, Daniel W. Seufert, Srivamsi Nekkalapudi, Nichole L. Prescott, Lisa E. Kelly and Milan Jamrich Int. J. Dev. Biol. (2005) 49: 881-884

\section{Regulation of vertebrate eye development by Rx genes}

Travis J. Bailey, Heithem El-Hodiri, Li Zhang, Rina Shah, Peter H. Mathers and Milan Jamrich

Int. J. Dev. Biol. (2004) 48: 761-770

\section{A moving wave patterns the cone photoreceptor mosaic array in the zebrafish retina}

Pamela A. Raymond and Linda K. Barthel

Int. J. Dev. Biol. (2004) 48: 935-945

\section{Genetics of photoreceptor development and function in zebrafish}

Motokazu Tsujikawa and Jarema Malicki

Int. J. Dev. Biol. (2004) 48: 925-934

Historical perspective on the development and evolution of eyes and photoreceptors

Walter J. Gehring

Int. J. Dev. Biol. (2004) 48: 707-717

\section{Evolution of eyes and photoreceptor cell types.}

Detlev Arendt

Int. J. Dev. Biol. (2003) 47: 563-571

Evolution and developmental expression of nuclear receptor genes in the ascidian Herdmania. Christine Devine, Veronica F Hinman and Bernard M Degnan

Int. J. Dev. Biol. (2002) 46: 687-692

Expression of the mediators of dioxin toxicity, aryl hydrocarbon receptor (AHR) and the AHR nuclear translocator (ARNT), is developmentally regulated in mouse teeth.

Carin Sahlberg, Raimo Pohjanvirta, Yuguang Gao, Satu Alaluusua, Jouko Tuomisto and Pirjo-Liisa Lukinmaa Int. J. Dev. Biol. (2002) 46: 295-300 